\title{
Çalışan Üniversite Öğrencilerinin Benlik Saygısı ve Psikolojik Dayanıklılık Düzeylerinin İncelenmesi
}

\author{
Lütfiye SÖĞÜTLÜ ${ }^{1}$ \\ Ahmet Hamdi İMAMOĞLU ${ }^{2}$ \\ Abdüllatif Ramazan ÇELİK ${ }^{3}$ \\ Yasin KARABULUT ${ }^{4}$
}

\begin{abstract}
$\overline{\mathbf{O Z Z}}$
Üniversite eğitimi sirasında istihdama katılan öğrencilerin sayısı her geçen yll artmakta ve bu durum çalışan üniversite ögrrencilerindeki psikolojik işlevselliğin incelenmesini önemli hale getirmektedir. Bu bağlamda mevcut araştırmada çalışan ve çalışmayan üniversite ögrrencilerinin benlik saygıları ve psikolojik dayanıkllikları karşılaştırılmıştır. Araştırmaya İstanbul Sağllk Bilimleri Üniversitesi’nde öğrenim gören 446 ögrenci dahil edilmiştir. Veri toplama işlemleri için Kişisel Bilgi Formu, Rosenberg Benlik Saygısı Ölçeği ve Psikolojik Dayanıklılık Ölçeği kullanılmıştır. Araştırma bulguları çalışan üniversite öğrencilerinde benlik saygısı ile psikolojik dayanıklılı̆̆ın alt faktörlerinden olan olumlu kendilik algısının ve sosyal yeterliliğ̈in çalışmayan ögrencilere klyasla daha yüksek olduğunu ortaya koymuştur. Bununla birlikte benlik saygısı arttıkça psikolojik dayanıklılığın da arttı̆̆ gözlemlenmişstir. Bulgular konuya ilişskin literatür çerçevesinde tartışılmış ve araştırmanın sinırlllıkları üzerinde durulmuştur.
\end{abstract}

Anahtar kelimeler: Benlik saygısı, psikolojik dayanıklılık, çalışan öğrenci

Investigation of self-esteem and psychological resilience levels among working university students

Abstract

The number of students participating in employment during university education is increasing every year and this increase makes it important to examine the psychological functionality of working university students. In the present study, the selfesteem and psychological resilience of working and non-working university students were compared. 446 students studying at Istanbul University of Health Sciences were included in the study. Personal Information Form, Rosenberg Self-Esteem Scale and Psychological Resilience Scale were used for data collection. Research findings revealed that positive self-perception and social competence, which are sub-factors of psychological resilience, and self-esteem, are higher in working university students compared to non-working students. Moreover, the correlation between self-esteem and psychological resilience was found to be significant. The findings were discussed within the framework of the relevant literature and the limitations of the study were emphasized.

Keywords: Self-esteem, psychological resilience, working student

\footnotetext{
${ }^{1}$ Dr. Öğr. Üyesi, Sağlık Bilimleri Üniversitesi, lutfiyeulgeli@hotmail.com, ORCID: 0000-0002-6078-9512.

${ }^{2}$ Psikolog, Sağlık Bilimleri Üniversitesi, ahmet.imamoglu@sbu.edu.tr, ORCID: 0000-0002-2176-7775.

${ }^{3}$ Psikoloji Bölümü Lisans Öğrencisi, Sağlık Bilimleri Üniversitesi, celikabdullatiframazan@gmail.com, ORCID: 00000002-5610-7451.

${ }^{4}$ Psikoloji Bölümü Lisans Öğrencisi, Sağlık Bilimleri Üniversitesi, yasinkarabulut.psy@gmail.com, ORCID: 0000-00024451-5717.

Makale Geliş Tarihi: 08.02.2021, Makale Kabul Tarihi: 27.06.2021
}

\section{ARAŞTIRMA MAKALESİ (Research Article)}

*Bu makale intihal programında taranmış ve en az iki hakem incelemesinden geçmiştir. (This article has been scanned via a plagiarism software and reviewed by at least two referees).

Doi: https://doi.org/10.51524/uhusbad.876766 


\section{Uluslararası Hukuk ve Sosyal Bilim Araştırmaları Dergisi \\ Uhusbad, Cilt 3, Sayı 1, 2021 (36-46)}

\section{Giriş}

Ergenlik döneminin son yılları bireyde psikolojik, biyolojik ve sosyal açıdan ortaya çıkan değişimlerin sürdüğü bir süreç olmakla birlikte, bu dönemde yetişkin yaşantısına uyum sağlamaya yönelik kazanımlar elde edilmektedir.Bu durum özellikle bu yıllarda uygulanması gereken koruyucu ruh sağlığı hizmetlerinin önemini arttırmaktadır (Santrock, 2014). Geç ergenlikten genç yetişkinliğe geçiş yıllarına tekabül eden üniversite eğitimi de öğrencilerin büyük çoğunluğunda biyopsikososyal değişimlerin yaşandığı bir süreç olarak deneyimlenmektedir. Bu süreçte yaşanan değişimlere ek olarak pek çok birey, hem yükseköğrenimi sürdürmek hem de istihdama katılmak gibi psikolojik kaynakların yoğun kullanımını ve uyum sağlamayı gerektiren bir akış içerisinde hareket etmektedir. Başka bir deyişle bu dönemde istihdama katılan bireyler, hem ergenlik dönemin getirdiği değişimlerle baş etmeye çalışırken hem de erken yaşta istihdama katılarak bir yetişkin gibi sorumluluk almaktadırlar (Razı vd., 2009). Ekonomik Kalkınma ve İşbirliği Örgütü'nün (OECD) yayınladığ 1 analizde 16-29 yaş grubunda hem istihdama katılan hem de ögrenimine devam eden bireylerin oranı İtalya'da \%15, Fransa'da \%22, İngiltere'de $\% 47$, ABD'de $\% 57$, Hollanda da ise $\% 63$ olarak belirtilmiştir. Türkiye'de 2020 y1lında bu oran \%42.2'dir (OECD, 2021).Bu yüksek oranlar çalışan öğrencilerinin sosyal, psikolojik ve fiziksel durumlarını ele almanın önemini ortaya koymaktadır (Benvegnu vd., 2005). İstihdama katılan ergenler üzerinde yapılan çalışmaların bazıları istihdamın olumlu etkisi olduğundan bahsederken (Coates, 2015), bir kısmı da özellikle çalışma şartlarına bağlı olarak olumsuz sonuçlara dikkat çekmektedir (Bachman \& Schulenberg, 1993). Bununla birlikte özellikle ülkemizde çalışan ergenlerin ve genç yetişkinlerin psikolojik işlevselliklerine ilişkin yapılan çalışmalar sınırlıdır (Bildik vd., 2004).

Psikolojik işlevsellikte merkezi bir rolü olan benlik saygısı kavramı bütüncül bir öz-değerlendirmeyi ifade etmektedir (Harter, 2006). Bireyin kendi değerine yönelik öznel algısında belirleyici olmasının yanında, benlik saygısının sosyal ilişkileri düzenlemede ve benliği korumada önemli işlevleri bulunmaktadır (Zeigler-Hill, 2013).Yüksek benlik saygısına sahip birey sosyal çevresi tarafından sevildiğini, güvenilir bir kişi olduğunu düşünür; kendini sever, yeteneklerinin farkındadır ve mevcut yetenek ve becerilerini geliştirmeye odaklanır. Bu açıdan bu bireyler psikopatolojik olarak daha düşük riske sahiptir (Waldron vd, 2018). Konuya ilişkin literatürdeki pek çok çalışma benlik saygısının psikopatolojilerdeki rolünü ortaya koymaktadır(Lynum vd,. 2008, Lee ve Hankin, 2009, Bos vd., 2010).Bu bağlamda benliğe yönelik olumlu değerlendirmelerin koruyucu bir faktör veya psikolojik işlevselliğin bir sonucu olabileceği tartışılmaktadır (Zeigler-Hill 2011). Sosyal (Marshall vd., 2014) ve akademik (Forsyth vd., 2007) bağlam ile iş ortamının (Schwalbe, 1988)da benlik saygısıyla yakından ilişkili olduğu vurgulanmaktadır.Özellikle yetişkinliğe geçiş döneminde gençlerin hayata bakış açılarını ve becerilerini geliştirecek iş ortamlarında bulunmalarının onların benlik saygılarını olumlu yönde etkileyebileceği bir gerçektir.Benliğe yönelik algı ile uyum ve başa çıkma mekanizmalarının gelişiminde belirleyici olabilecek bu süreç göz önüne alındığında benlik saygısı bağlamında yapılmış çalışmaların sınırlı sayıda olduğu dikkat çekmektedir.

Psikolojik işlevsellikte önemli bir yer tutan diğer bir kavram psikolojik dayanıklılıktır. Hunter (2001) psikolojik dayanıklılığı genel olarak bir başarı veya uyum sağlama süreci olarak ifade etmektedir. Başka bir deyişle psikolojik dayanıklılık zorlu yaşamsal olayların karşısında bireyin kendini toparlama gücüdür (Garmezy, 1991). Bu bağlamda üniversiteli gençlerdeki yüksek psikolojik dayanıklılığı, fizyolojik ve psikolojik gelişimin senkronize olmasını, bireyin bunlara adapte olabilmesini ve bu dönemdeki kazanımları sürdürebilmesini kolaylaştıran bir faktör olarak değerlendirmek mümkündür. Bu durum gençlerin hayatları boyunca edindikleri olumlu veya olumsuz kimlikleri eğitim yıllarınayansıtabileceklerine işaret etmektedir (Earvolino-Ramirez, 2007). Nitekim psikolojik dayanıklılığın akademik performans ile ilişkili olduğunu gösteren çalışmalar bulunmaktadır (Ayala \&Manzano, 2018). Sınırlı sayıdaki araştırmada da çalışan üniversite öğrencilerinde psikolojik dayanıklılığın daha yüksek olduğu rapor edilmiştir (Chung vd., 2017).

Mevcut araştırmanın temel amacı istihdama katılan üniversite öğrencilerinin ve istihdama katılmadan öğrenimine devam eden üniversite öğrencilerinin benlik saygılarını ve psikolojik dayanıklılıklarını karşılaştırmaktır. Çalışma sürecinin öğrencilere sunduğu olumlu ve olumsuz psikolojik süreçler daha 


\section{Uluslararası Hukuk ve Sosyal Bilim Araştırmaları Dergisi \\ Uhusbad, Cilt 3, Sayı 1, 2021 (36-46)}

kapsamlı incelendikçe bu dönemde sağlanacak istihdamın koşulları ve gerekliliği ile ilgili bilgimizin artması beklenmektedir.

\section{Yöntem}

\section{Örneklem}

$\mathrm{Bu}$ araştırma istihdama katılan üniversite öğrencilerinde benlik saygısı ve psikolojik dayanıklılık düzeylerini saptamayı amaçlayan kesitsel, betimsel ve karşılaştırmalı bir çalışmadır. Yükseköğretim kurumu bilgi yönetim sistemi verilerine göre İstanbul ilinde yaklaşık 1.5 milyon üniversite öğrencisi bulunmaktadır (TÜİK, 2021). Buna göre örnekleme hatası 0.05 olarak alındığında evrenden çekilmesi gereken örneklem büyüklüğü 384 olarak belirlenmiştir (Yazıcığlu \& Erdoğan, 2004).Bu bağlamda 'uygun örnekleme yöntemi' (convenience sampling) kullanılarak Sağlık Bilimleri Üniversitesi Hamidiye Kampüsü'nde öğrenimine devam eden 460 öğrenciye ulaşılmıştır. Katılımcıların 14 tanesi uç değerler sebebiyle veri analizinin dışında tutulmuştur. Veri analizlerinin yürütüldüğg̈ 446 katılımcının yaş ortalaması 20,84 (Ort= 20.84, $S=1.90)$ olarak hesaplanmıştır. Bununla birlikte katılımciların 287'sinin kadın (\%64.3), 158'sinin ise erkek (\%35.4) olduğu belirlenmiştir. Örneklem içerisinde ağırlıklı olarak (\%84.1) lisans programına kayıtlı öğrenciler bulunmaktadır. Herhangi bir işte çalışan öğrencilerin sayısının 217 (\%47.2), karşılaştırma gurubu olarak belirlenmiş olan herhangi bir işte çalışmayan öğrencilerin sayısının ise 243 (\%52.8) olduğu görülmüştür. Bir işte çalışan katılımcılar arasından 100 ’ü (\%49) çalıştığı işi düzenli bir iş olarak tanımlamaktadır.

\section{İşlem}

Araştırmanın yürütülmesi için Sağlık Bilimleri Üniversitesi Hamidiye Bilimsel Araştırmalar Etik Kurulu'ndan 46418926-050.01.04 sayı ile onay alınmıştır. Katılımcılara araştırmanın içeriği, amacı, önemi ve veri toplama formları ile ilgili açıklama yapıldıktan sonra, anket üzerinde kendi kişisel bilgileriyle ilgili herhangi bir sorunun yer almayacağı ve bu anketlere araştırmacılardan başka kimsenin ulaşamayacağ konusunda bilgilendirme yapılmıştır. Hazırlanmış olan bilgilendirilmiş gönüllü onam formu katılımcılara okutularak çalışmaya katılımın gönüllü olduğu ve herhangi bir aşamada çalışmaya katılmaktan vazgeçme haklarının bulunduğu anlatılmıştır. Araştırmaya katılmayı kabul eden katılımcılardan yazılı olarak onayları alınmıştır. Katılımcılar anketleri bireysel olarak doldurmuşlardır. Verilerin analizi için SPSS (Statistical PackageforSocialSciences) 21 paket programı kullanılmıştır. Normal dağılımı test etmek için Kolmogorov-Smirnov testi kullanılmıștır. Sürekli değişkenler ortalama \pm standart sapma olarak ifade edilmiştir. Kategorik veriler yüzde olarak sunuldu. İstatistiksel analizlerde kategorik değişkenlerin analizinde Ki-kare testi, sürekli değişkenlerin analizinde $t$ testi ve normal dağılım göstermeyen verilerin analizinde Mann-Whitney U testi kullanılmıştır.

\section{Veri Toplama Araçları}

Veri toplama araçları içerisinde literatür incelemeleri sonucu oluşturulan Kişisel Bilgi Formu, Rosenberg Benlik Saygısı Ölçeği (RBSÖ) ve Psikolojik Dayanıklılık Ölçeği (PDÖ) yer almaktadır.

Kişisel Bilgi Formu: Katılımcıların cinsiyeti, yaşı, kaçıncı sınıfta oldukları ve hangi bölümde okudukları, algıladıkları gelir düzeyi ve ailelerinin ikamet ettiği yerin özelliği (köy, kasaba, küçük şehir, büyük şehir) gibi bilgilerin sorulduğu kişisel bilgi formu kullanılmıştır.

Rosenberg Benlik Saygısı Ölçeği: Ölçek Rosenberg (1979) tarafından bireylerin kendi benliklerine yönelik öznel değerlendirmelerini ölçmek amacıyla geliştirilmiştir. Ölçeğin Türkiye'de güvenirlik ve geçerlilik çalışmaları Çuhadaroğlu (1986) tarafindan gerçekleştirilmiştir. Ölçeğin Türkçe geçerlilik ve güvenilirlik çalışmasında 0-1 puan yüksek düzeyde benlik saygısı, 2-4 puan orta düzeyde benlik saygısı, 5-6 puan düşük düzeyde benlik saygısı olarak değerlendirmeye alınmıştır. RBSÖ toplamda 12 alt boyuttan oluşmaktadır. Araştırmada sadece 10 maddeden oluşan genel benlik saygısı alt boyutu kullanılmıştır. Çuhadaroğlu (1986) tarafından (RBSÖ) Türkçe formu için yapılan güvenirlik 


\section{Uluslararası Hukuk ve Sosyal Bilim Araştırmaları Dergisi \\ Uhusbad, Cilt 3, Sayı 1, 2021 (36-46)}

çalışmasında, test-tekrar test güvenirlik katsayısının .48 ile.79 arasında değiştiği bulunmuştur. $\mathrm{Bu}$ araştırmada kullanılan alt ölçeğe ait Cronbach alfa iç tutarlılık katsayısı 0,88'dir.

Psikolojik Dayanıklılık Ölçeği: Psikolojik dayanıklılık ölçeği yetişkin formu, Friborg ve arkadaşları (2003) tarafından geliştirilmiş, Basım ve Çetin (2011) tarafından Türkçeye uyarlanmıştır. Ölçek 5'li likert tipinde 33 maddeden oluşmaktadır. Her maddenin cevap seçenekleri, o maddeye özel olarak belirlenmiştir. Ölçek kendilik algısı, gelecek algısı, yapısal stil, sosyal yeterlilik, aile uyumu ve sosyal kaynaklar olmak üzere 6 alt boyuttan oluşmaktadır. Türkçe uyarlama çalışmasında alt ölçeklerin Cronbach alfa iç tutarlılık katsayılarının .66 ile .81 arasında değiştiği, toplam ölçek için bu değerin .86 olduğu rapor edilmiştir (Basım \& Çetin, 2011).

\section{Bulgular}

Araştırmada ilk olarak katılımcıların çalışma durumlarının cinsiyete göre farklılaşıp farklılaşmadığını belirlemek amacıyla Ki-Kare testi uygulanmıştır (Tablo 1). Test sonucunda kadın katılımcıların, \%40.8'inin $(\mathrm{N}=117)$ bir işte çalışırken \%59.2'sinin $(\mathrm{N}=170)$ çalışmadı̆̆ 1 görülmüştür. Erkek katılımcılar içinse bu oranların sırasıyla \%54.4 $(\mathrm{N}=86)$ ve \%45.6 $(\mathrm{N}=72)$ olduğu tespit edilmiştir. Sonuçlara göre, katılımcıların cinsiyetlerine göre çalışma durumları anlamlı düzeyde farklılaşmaktadır $\left(\mathrm{X}^{2}=7.67, \mathrm{p}<.05\right)$.

Tablo 1. Katılımcıların Çalışma Durumunun Cinsiyet Açısından Karşılaştırılması

\begin{tabular}{|c|c|c|c|c|c|c|c|}
\hline & & \multicolumn{2}{|c|}{ İş Durumu } & \multirow[t]{2}{*}{ Toplam } & \multirow[t]{2}{*}{$\mathrm{X}^{2}$} & \multirow{2}{*}{$\begin{array}{c}\text { Serbestlik } \\
\text { Derecesi } \\
\end{array}$} & \multirow[t]{2}{*}{$\mathrm{p}$} \\
\hline & & Çalışıyor & Çalışmıyor & & & & \\
\hline Cinsiyet & $\begin{array}{l}\text { Kadın } \\
\text { Erkek }\end{array}$ & $\begin{array}{c}117 \\
86\end{array}$ & $\begin{array}{c}170 \\
72\end{array}$ & $\begin{array}{l}287 \\
158\end{array}$ & 7.67 & 1 & .01 \\
\hline Toplam & & 203 & 242 & & & & \\
\hline
\end{tabular}

Çalışmada ikinci olarak, PDÖ toplam puanı ve alt ölçek puanları ile RBSÖ puanlarının katılımcıların çalışma durumuna göre değişip değişmediğini belirlemek amacıyla bir dizi bağımsız gruplar $\mathrm{t}$ testi yürütülmüştür (Tablo 2).

Tablo 2.Katılımcıların Çalışma Durumuna Göre Benlik Saygısı ve Psikolojik Dayanıklılık Puanlarının Karşılaştırılması

\begin{tabular}{|c|c|c|c|c|c|c|}
\hline & \multicolumn{4}{|c|}{ İş Durumu } & \multirow{3}{*}{$\mathrm{t}$} & \multirow{3}{*}{$\mathrm{p}$} \\
\hline & \multicolumn{2}{|c|}{$\begin{array}{l}\text { Çalışıyor } \\
(\mathrm{N}=204)\end{array}$} & \multicolumn{2}{|c|}{$\begin{array}{l}\text { Çalışmıyor } \\
(\mathrm{N}=242)\end{array}$} & & \\
\hline & Ort. & SS & Ort. & SS & & \\
\hline Benlik Saygısı & 1.2 & 1.52 & 2.03 & 1.74 & 1.14 & .02 \\
\hline $\begin{array}{l}\text { Psikolojik Dayanıklılik } \\
\text { (Toplam Puan) }\end{array}$ & 121.00 & 18.92 & 119.06 & 15.91 & 1.16 & .25 \\
\hline $\begin{array}{l}\text { Psikolojik Dayanıklılık } \\
\text { (Kendilik Algisı) }\end{array}$ & 22.44 & 4.63 & 21.33 & 4.13 & 2.68 & .01 \\
\hline
\end{tabular}




\begin{tabular}{|c|c|c|c|c|c|c|}
\hline $\begin{array}{l}\text { Psikolojik Dayanıklılık } \\
\text { (Gelecek Algısı) }\end{array}$ & 15.20 & 3.53 & 15.09 & 3.32 & .34 & .74 \\
\hline $\begin{array}{l}\text { Psikolojik Dayanıklılık } \\
\text { (Yapısal Stil) }\end{array}$ & 14.20 & 3.52 & 13.85 & 3.02 & 1.10 & .27 \\
\hline $\begin{array}{l}\text { Psikolojik Dayanıklılık } \\
\text { (Sosyal Yeterlilik) }\end{array}$ & 22.40 & 4.56 & 21.41 & 4.25 & 2.37 & .02 \\
\hline $\begin{array}{l}\text { Psikolojik Dayanıklılık } \\
\text { (Aile Uyumu) }\end{array}$ & 20.29 & 5.02 & 20.38 & 4.79 & -.20 & .84 \\
\hline $\begin{array}{l}\text { Psikolojik Dayanıklılık } \\
\text { (Sosyal Kaynaklar) }\end{array}$ & 26.41 & 5.19 & 26.99 & 4.34 & -1.26 & .21 \\
\hline
\end{tabular}

Sonuçlara göre PDÖ alt ölçeklerinden Kendilik Algısı $(\mathrm{t}=2.68, \mathrm{p}<.05)$ ve Sosyal Yeterlilik $(\mathrm{t}=2.37$, $\mathrm{p}<.05)$ puanlarının öğrencilerin çalışma durumuna göre anlamlı düzeyde farklılaştı̆̆ 1 görülmektedir. Başka bir ifadeyle bir işte çalışan katılımcıların Kendilik Algısı puanlarının ( $\overline{\mathrm{x}}=22.44$, ss=4.63) çalışmayan katılımcılarınkine $(\overline{\mathrm{x}}=21.33$, ss=4.13) kıyasla anlamlı şekilde daha yüksek olduğu tespit edilmiştir $(\mathrm{t}=2.68, \mathrm{p}<.05)$. Benzer şekilde çalışan katılımcıların Sosyal Yeterlilik alt ölçeğinden $(\overline{\mathrm{x}}=22.40, \mathrm{ss}=4.56)$ çalışmayan katılımcılarınkine $(\overline{\mathrm{x}}=21.41$, ss $=4.25)$ kiyasla anlamlı şekilde daha yüksek düzeyde puanlar elde ettiği görülmüştür $(\mathrm{t}=2.37, \mathrm{p}<.05)$. PDÖ’nün diğer alt ölçekleri ve toplam puanının ise çalışma durumuna göre farklılaşmadığı bulunmuştur (PDÖ toplam puan $\mathrm{t}=1.16, \mathrm{p}=.25$, PDÖ Gelecek Algisı t=.34, p=.74, PDÖ Yapısal Stil t=1.10, p=.27, PDÖ Aile Uyumu $t=-.20, p=.84$, PDÖ Sosyal Kaynaklar $\mathrm{t}=-1.26, \mathrm{p}=.21$ ). Öte yandan RBSÖ puanlarının çalışma durumuna göre farklılaştığı görülmektedir $(\mathrm{t}=1.14, \mathrm{p}<.05)$. RBSÖ puanları arttıkça benlik saygısının azaldığı göz önüne alındığında, bir işte çalışan grubun benlik saygısının ( $\overline{\mathrm{x}}=1.2$, ss=1.52), bir işte çalışmayan grubun benlik saygısına $(\overline{\mathrm{x}}=2.03$, ss=1.74) kıyasla anlamlı şekilde daha yüksek olduğunu söylemek mümkündür $(\mathrm{t}=1.14, \mathrm{p}=.02)$. Bununla birlikte çalışan öğrenciler içerisinde düzenli bir işte çalıştığını belirten grupla, düzenli bir işte çalışmadığını belirten grup arasında benlik saygısı ve psikolojik dayanıklılık puanları açısından bir fark olmadığı görülmüştür.

Son olarak, araştırmada yer alan değişkenler arasındaki ilişkiyi incelemek amacıyla Pearson Momentler Çarpımı Korelasyon Katsayıları hesaplanmıştır (Tablo 3). 
Tablo 3.Araştırmada Yer Alan Değişkenler Arasındaki Korelasyon Değerleri

\begin{tabular}{|c|c|c|c|c|c|c|c|c|}
\hline & 1 & 2 & 3 & 4 & 5 & 6 & 7 & 8 \\
\hline 1. PDÖ Toplam & - & & & & & & & \\
\hline 2. PDÖ Kendilik Algısı & $.73^{*}$ & - & & & & & & \\
\hline 3. PDÖ Gelecek Algisı & $.74 *$ & $.63^{*}$ & - & & & & & \\
\hline 4. PDÖ Yapısal Stil & $.56^{*}$ & $.33^{*}$ & $.42 *$ & - & & & & \\
\hline $\begin{array}{l}5 . \quad \text { PDÖ Sosyal } \\
\text { Yeterlilik }\end{array}$ & $.67 *$ & $.41^{*}$ & $.45^{*}$ & $.22^{*}$ & - & & & \\
\hline 6. PDÖ Aile Uyumu & $.65^{*}$ & $.31 *$ & $.30 *$ & $.25^{*}$ & $.17^{*}$ & - & & \\
\hline $\begin{array}{l}\text { 7. PDÖ Sosyal } \\
\text { Kaynaklar }\end{array}$ & $.77 *$ & $.37 *$ & $.40^{*}$ & $.28^{*}$ & $.50 *$ & $.51^{*}$ & - & \\
\hline 8. Benlik Saygısı & $-.56 *$ & $-.53 *$ & $-.50 *$ & $-.27 *$ & $-.35 *$ & $-.35 *$ & $-.34 *$ & - \\
\hline Ort. & $\begin{array}{c}119.9 \\
5\end{array}$ & 21.84 & 15.14 & 14.01 & 21.87 & 20.34 & 26.73 & 2.02 \\
\hline SS & 17.36 & 4.40 & 3.42 & 3.26 & 4.42 & 4.89 & 4.75 & 1.69 \\
\hline
\end{tabular}

*p <.001, PDÖ: Psikolojik Dayanıklılık Ölçeği

Sonuçlar katılımcıların PDÖ toplam puanı ile RBSÖ puanları arasında negatif düzeyde anlamlı bir ilişki olduğuna işaret etmektedir ( $\mathrm{r}=-.56, \mathrm{p}<.001)$. Başka bir ifadeyle katılımcıların psikolojik dayanıklılığı arttıkça RBSÖ'den aldıkları puanların düştüğü, yani benlik saygılarının arttığı gözlemlenmektedir. Benzer şekilde PDÖ'nün alt ölçekleri ile RBSÖ puanları arasında $\mathrm{r}=-.27$ ile $\mathrm{r}=-.53$ arasında değişen korelasyon katsayıları bulunmuştur $(\mathrm{p}<.001)$. Yani psikolojik dayanıklılığa ilişkin faktörlerde gözlemlenen artışla birlikte benlik saygısı da anlamlı düzeyde yükselmektedir. Ayrıca PDÖ’nün alt faktörleri ile toplam puanı arasındaki korelasyon katsayılarının $r=.56$ ile $r=.73$ arasında değiştiği görülmüştür $(\mathrm{p}<.001)$.

\section{Tartışma}

Eğitim hayatı günümüzde çoğu gencin bir önceliği olsa da bazı öğrenciler şartlarını zorlayarak yarı zamanlı veya tam zamanlı işlerde çalışabilmektedir.Türkiye İstatistik Kurumu (TÜIK) verilerine göre 15-24 yaş arası genç nüfusun işgücüne katılım oranı 2014 yılında \%37.6 iken 2020 yılında bu oran \%42.1'e yükselmiştir (data.tuik.gov.tr, 2020). Buna göre eğitimine devam ederken istihdama katılım gösteren bireylerin sayısı her geçen yıl artmaktadır. Dolayısıyla çalışan üniversite öğrencilerinin psikolojik profillerini incelemeye yönelik araştırmalar da giderek önem kazanmaktadır. Özellikle ülkemizde bu konudaki çalışmaların oldukça sınırlı olduğu görülmektedir.

Mevcut çalışmanın bulguları öğrenimine devam ederken bir işte çalışan üniversite öğrencilerinin benlik saygılarının çalışmayan öğrencilere kıyasla daha yüksek olduğuna işaret etmektedir. Ayrıca bu ögrencilerde psikolojik dayanıklılı̆̆ın faktörlerinden olan kendilik algısının daha olumlu ve sosyal yeterlik algısının ise daha yüksek olduğu görülmüştür. Literatürdeki bazı çalışmalar bu bulgularla paralel şekilde istihdama katılmanın öğrencilerde olumlu psikolojik çıktılarla ilişkili olabileceğini ortaya koymaktadır. Örneğin Christiansen vd. (2019), bir işte çalışmanın öğrencilerin ekonomik bağımsızlığını ve başarma hissini destekleyebileceğini ve benlik saygılarını geliştirebileceğini aktarmaktadır. Benzer şekilde haftalık 35 saatten daha fazla çalışan üniversite öğrencilerinin çalışmayanlara kıyasla daha 


\section{Uluslararası Hukuk ve Sosyal Bilim Araştırmaları Dergisi \\ Uhusbad, Cilt 3, Sayı 1, 2021 (36-46)}

yüksek düzeyde psikolojik dayanıklılığa sahip olduğu rapor edilmiştir (Chung vd., 2017). Başka bir araştırmada ise çalışan üniversite öğrencilerinin tükenmişlik düzeylerinin daha düşük olduğu dikkat çekmiştir (Kutylo, 2019).Öte yandan bu öğrencilerin eğitimleri sırasında çalışıyor olmalarının mezuniyetleri sonrasında iş bulabilmelerini kolaylaştıracak becerilerin gelişimine katkı sağlayabileceği öne sürülmektedir (Coates, 2015). Bu bağlamda üniversite eğitimine devam ederken istihdama katılan gençlerin mevcut yaşam zorlukları karşısında dirençlerinin, baş etme mekanizmalarının ve sosyal ağlarının gelişiyor olabileceği, böylece benliklerine ve sosyal becerilerine yönelik algılarının olumlu etkilenebileceğini söylemek mümkündür.Ayrıca mevcut çalışmanın örneklemindeki istihdama katılmış öğrencilerin \%48.5'i elde ettiğ gelirle kendi geçimini sağladıklarını, \%51.5'i ise elde ettiğ $i$ gelirle yakınlarının geçimine destek olduklarını bildirmektedir. Bu faktörlerin de benlik saygısına ve psikolojik dayanıklılığa katkıda bulunabileceği düşünülmektedir. Başka bir açıdan bakıldığında ise mevcut bulguların, psikolojik dayanıklılığı ve benlik saygısı daha yüksek olan gençlerde bir işe başlama ve işi sürdürme eğiliminin daha yüksek olmasının bir sonucu olabileceğini söylemek mümkündür.

Literatürdeki bazı araştırmalar, istihdama katılmış olmanın gençlerde psikolojik ve akademik açıdan olumsuz sonuçlarla ilişkili olabileceğini ortaya koymaktadır.Örneğin Hemşirelik Fakültesi 1. Sınıf öğrencileri ile yapılan bir çalışmada; tam zamanlı bir işte haftada 20 saat ve üzeri çalışan öğrencilerin kişisel kaynaklarının zorlandığı ve ders notlarının düştüğü belirtilmiştir (Salamonson, 2018).Benzer şekilde çalışırken öğrenimine devam üniversite öğrencileri ile yapılan bir diğer çalışmada da artan çalışma saatleri ile not ortalaması arasında negatif bir ilişki saptanmıştır (Salamonson, 2020). Çalışan ve çalışmayan öğrencilerin karşılaştırıldığı bir çalışmada iki grup arasında depresyon düzeyleri ve not ortalamaları arasında bir fark saptanamamıştır, ancak çalışan grupta kaygı düzeylerinin daha yüksek olduğu ve sosyal desteğin ise daha düşük olduğu belirlenmiştir (Maunsey, 2013).Mevcut çalışmada çalışma durumunun öğrencilerin not ortalaması üzerine herhangi bir etkisi tespit edilmemiştir. Bu bulgular istihdama katılan öğrencilerde çalışma şartlarının önemine dikkat çekmektedir. Yoğun çalışma saatleri, sosyalleşmeye daha az katılım, ekonomik şartlardan dolayı mecburen iş hayatına atılma gibi faktörlerin gençlerin başa çıkma mekanizmalarını zorlayarak psikolojik ve akademik işlevselliklerini olumsuz etkileyebileceği anlaşılmaktadır. Nitekim ülkemizde yapılan bir çalışmada 6 gün ve üzerinde çalışan gençlerin 6 günden daha az çalışan gençlere göre daha düşük düzeyde benlik saygısına sahip olduğu görülmüştür (Razı vd., 2009).

Mevcut çalışmada gençlerde psikolojik dayanaklılık ve benlik saygısı arasında anlamlı bir ilişki olduğu görülmektedir. Buna göre benlik saygısı yükseldikçe psikolojik dayanıklılığın da arttığı anlaşılmaktadır. Benlik saygısının olumsuz yaşantılar karşısında benliği koruma işlevi göz önüne alındığında bu şekildeki bir ilişki gözlemlenmesinin makul olduğu düşünülmektedir. Benzer şekilde psikolojik dayanıklılık arttıkça kişinin kendi kaynaklarına duyacağı güven artacağından benlik saygısının da buna paralel olarak yükselmesi olası görünmektedir. Mevcut çalışma ile uyumlu şekilde literatürdeki pek çok araştırma bu iki yapı arasında benzer bir korelasyon olduğunu ortaya koymaktadır (Arslan, 2016; Soylu, 2018; Akhtar \& Bilour, 2020; Kaya \& Şarl1, 2020). Bu bağlamda birbiriyle ilişkili bu iki yapının gençlerin psikolojik işlevselliğindeki rolü dikkat çekmektedir. Ülkemizde üniversite öğrencileri ile yapılan bir çalışmada yaşam doyumu ile psikolojik dayanıklılık arasındaki ilişkide benlik saygısının aracı rolü ortaya konmuştur (Temiz, 2017).

Son olarak mevcut araştırmanın, bulguları değerlendirmede göz önünde bulundurulması gereken bazı sınırlılıklar bulunmaktadır. Öncelikle araştırma verileri öz-bildirim ölçeklerine dayandığından elde edilen sonuçlar katılımcıların öznel değerlendirmelerini yansıtmaktadır. Ayrıca çalışma durumunun öğrencilerin psikolojik işlevselliğindeki olası etkileri tartışılmış olsa da araştırma yapısı itibariyle bu yönde bir nedensellik ortaya koymaktan ziyade, gruplar arası farklara odaklanmıştır. Bununla birlikte araştırma örneklemini İstanbul ilindeki bir devlet üniversitesinde öğrenim gören katılımcılar oluşturduğundan, bulguların genellenebilirliği konusunda dikkatli olunmalıdır. Konuya ilişkin gelecek araştırmalara farklı şehirlerden ve üniversitelerden öğrencilerin dahil edilmesi ve farklı çalışma koşullarının öğrenciler üzerindeki etkilerinin ele alınması önerilmektedir. 


\section{BEYANLAR}

Etik Kurul Onayı: Yazılı izinler Sağlı Bilimleri Üniversitesi Hamidiye Bilimsel Araştırmalar Etik Kurulu'ndan 46418926-050.01.04 sayılı belge ile alınmıştır.

Katılımcı Onamı: Tüm katılımcılar ücretsiz ve bilgilendirilmiş katılımcı onam formunu imzalamıştır.

Hakem Değerlendirme Süreci: Dışarıdan hakemli.

Çıkar Çatışması Beyanı: Yazarların herhangi bir çıkar çatışması yoktur.

Finansal Destek: Yazarlar bu çalışma için mali destek almamıştır.

Katkı Payı Oranı: Tüm yazarlar eşit oranda makaleye katılım sağlamıştır (\%25, \%25, \%25, \%25). Yazarların tamamı, tasarım, uygulama ve analiz süreçlerine katılmışır. 


\section{Uluslararası Hukuk ve Sosyal Bilim Araştırmaları Dergisi \\ Uhusbad, Cilt 3, Sayı 1, 2021 (36-46)}

\section{KAYNAKÇA}

Akhtar, M., \& Bilour, N. (2019). State of mental health among transgender individuals in Pakistan: Psychological resilience and self-esteem. Community mental health journal, 1-9.

Arslan, G. (2016). Psychological maltreatment, emotional and behavioral problems in adolescents: The mediating role of resilience and self-esteem. Child Abuse \& Neglect, 52, 200-209.

Ayala, J. C., \& Manzano, G. (2018). Academic performance of first-year university students: The influence of resilience and engagement. Higher Education Research \& Development, 37(7), 1321-1335.

Bachman, J. G., \& Schulenberg, J. (1993). How part-time work intensity relates to drug use, problem behavior, time use, and satisfaction among high school seniors: Are these consequences or merely correlates?. Developmental Psychology, 29(2), 220.

Basim, H. N., \& Cetin, F. (2011). The reliability and validity of the Resilience Scale for Adults-Turkish Version. Turk Psikiyatri Derg, 22(2), 104.

Benvegnú, L. A., Fassa, A. G., Facchini, L. A., Wegman, D. H., \& Dall'Agnol, M. M. (2005). Work and behavioural problems in children and adolescents. International journal of epidemiology, 34(6), 14171424.

Bildik, T., Büküşoğlu, N., \& Kesikçi, H. (2004). Çalişan Ergenlerin Psikososyal Sorunlari Ve Kendi Çözüm Önerileri. Ege Tip Dergisi, 43(2), 105-111.

Bos, A. E., Huijding, J., Muris, P., Vogel, L. R., \& Biesheuvel, J. (2010). Global, contingent and implicit selfesteem and psychopathological symptoms in adolescents. Personality and Individual Differences, 48(3), 311-316.

Christiansen, A., Salamonson, Y., Crawford, R., McGrath, B., Roach, D., Wall, P., ... \& Ramjan, L. M. (2019). "Juggling many balls": Working and studying among first-year nursing students. Journal of clinical nursing, 28(21-22), 4035-4043.

Chung, E., Turnbull, D., \& Chur-Hansen, A. (2017). Differences in resilience between 'traditional'and 'nontraditional'university students. Active Learning in Higher Education, 18(1), 77-87.

Coates, H. (2015). Working on a dream: Educational returns from off-campus paid work. Journal of Education and Work, 28(1), 66-82.

Çuhadaroğlu,F. (1986). Adolesanlarda Benlik Saygısı (Yayınlanmamış Uzmanlık Tezi). Hacettepe Üniversitesi, Ankara.

Earvolino-Ramirez, M. (2007, April). Resilience: A concept analysis. In Nursing forum (Vol. 42, No. 2, pp. 7382). Malden, USA: Blackwell Publishing Inc.

Forsyth, D. R., Lawrence, N. K., Burnette, J. L., \& Baumeister, R. F. (2007). Attempting to improve the academic performance of struggling college students by bolstering their self-esteem: An intervention that backfired. Journal of Social and Clinical Psychology, 26(4), 447-459.

Friborg, O., Hjemdal, O., Rosenvinge, J. H., \& Martinussen, M. (2003). A new rating scale for adult resilience: what are the central protective resources behind healthy adjustment?. International journal of methods in psychiatric research, 12(2), 65-76.

Garmezy, N. (1991). Resilience in children's adaptation to negative life events and stressed environments. Pediatric annals, 20(9), 459-466.

Harter, S. (2006). The development of self-esteem In: Kernis M, editor. Self-esteem issues and answers: A sourcebook of current perspectives. 


\section{Uluslararası Hukuk ve Sosyal Bilim Araştırmaları Dergisi \\ Uhusbad, Cilt 3, Sayı 1, 2021 (36-46)}

Hunter A. J. (2001). A cross-cultural comparison of resilience in adolescents. Journal of pediatric nursing, 16(3), 172-179.

Kaya, F. Ş., \& Şarlı, E. Spor Bilimleri Fakültesinde Öğrenim Gören Öğrencilerin Problem Çözme Becerilerinin Psikolojik Dayanıklılık ve Benlik Saygısı ile İlişkisi. Eurasian Research in Sport Science, 5(1), 60-77.

Kutyło, Ł., Łaska-Formejster, A. B., \& Ober-Domagalska, B. (2019). Fatigue among working and non-working students: a sociological analysis of the environmental determinants of its level. Medycyna pracy, 70(5), 597-609.

Lee, A., \& Hankin, B. L. (2009). Insecure attachment, dysfunctional attitudes, and low self-esteem predicting prospective symptoms of depression and anxiety during adolescence. Journal of clinical child \& Adolescent Psychology, 38(2), 219-231.

Lynum, L. I., Wilberg, T., \& Karterud, S. (2008). Self-esteem in patients with borderline and avoidant personality disorders. Scandinavian Journal of Psychology, 49(5), 469-477.

Marshall, S. L., Parker, P. D., Ciarrochi, J., \& Heaven, P. C. (2014). Is self-esteem a cause or consequence of social support? A 4-year longitudinal study. Child Development, 85(3), 1275-1291.

Mounsey, R., Vandehey, M., \& Diekhoff, G. (2013). Working and non-working university students: Anxiety, depression, and grade point average. College Student Journal, 47(2), 379-389.

OECD (2021), Unemployment rate (indicator). doi: 10.1787/52570002-en (Accessed on 08 February 2021).

Razı, G. S., Kuzu, A., Yıldız, A. N., Ocakcı, A. F., \& Arifoğlu, B. Ç. (2009). Çalışan Gençlerde Benlik Saygısı, İletişim Becerileri ve Stresle Baş Etme. TAF Preventive Medicine Bulletin, 8(1).

Rosenberg, M. (1979). Conceivingthe Self. New York: Basic Books.

Salamonson, Y., Priddis, H., Woodmass, J. M., Everett, B., Lynch, J., Curtis, E., \& Ramjan, L. M. (2018). The price of journeying towards the prize-Commencing nursing students' experiences of working and studying: A qualitative study. Journal of clinical nursing, 27(21-22), 4141-4149.

Salamonson, Y., Roach, D., Crawford, R., McGrath, B., Christiansen, A., Wall, P., ... \& Ramjan, L. M. (2020). The type and amount of paid work while studying influence academic performance of first year nursing students: An inception cohort study. Nurse education today, 84, 104213.

Santrock, J. W. (2014). Ergenlik (Çev. DM Siyez). Ankara: Nobel Akademik Yayıncılık.

Schwalbe, M. L. (1988). Sources of self-esteem in work: What's important for whom?. Work and Occupations, 15(1), 24-35.

Soylu, Y. (2018). Developing a Model to Explain Psychological Resilience among Divorced Women. Turkish Psychological Counseling and Guidance Journal, 8(49), 81-100.

Temiz, Z. T. (2017). Üniversite ögrencilerinin bağlanma stilleri ile yaşam doyumu, psikolojik dayanıklılık ve aleksitimik özellikleri arasındaki ilişkide benlik saygısının rolü (Master's thesis, Fatih Sultan Mehmet Vakıf Üniversitesi, Sosyal Bilimler Enstitüsü).

TÜİK,https://data.tuik.gov.tr/Kategori/GetKategori?p=istihdam-issizlik-ve-ucret-108\&dil=1

TÜİK, https://data.tuik.gov.tr/Kategori/GetKategori?p=Egitim,-Kultur,-Spor-ve-Turizm-105

Waldron, J. C., Scarpa, A., \& Kim-Spoon, J. (2018). Religiosity and interpersonal problems explain individual differences in self esteem among young adults with child maltreatment experiences. Child abuse \& neglect, 80, 277-284.

Yazıcıoğlu, Y. ve Erdoğan, S. (2004). Spss Uygulamalı Bilimsel Araştırma Yöntemleri. Ankara: Detay Yayıncılık. 
Uhusbad, Cilt 3, Sayı 1, 2021 (36-46)

Zeigler-Hill, V. (2011). The Connections Between Self-esteem and Psychopathology. Journal of Contemporary Psychotherapy, 41(3), 157-164.

Zeigler-Hill, V. (2013). The Importance of Self-esteem. V. Zeigler-Hill (Ed.), Self-esteem içinde (s. 1-20). New York, PsychologyPress. 